\title{
Expression profile-driven discovery of AURKA as a treatment target for liposarcoma
}

\author{
CHUEH-CHUAN YEN ${ }^{1,2,5}$, SAN-CHI CHEN ${ }^{1,2,5}$, GIUN-YI HUNG ${ }^{2,3,5}$, PO-KUEI WU ${ }^{2,4,5}$, \\ WEI-YANG CHUA ${ }^{1}$, YUNG-CHAN LIN ${ }^{1}$, CHIAO-HAN YEN ${ }^{1}$, YEN-CHUN CHEN ${ }^{1}$, JIR-YOU WANG ${ }^{2,4,5}$, \\ MUH-HWA YANG ${ }^{1,5}$, YEE CHAO ${ }^{1,5}$, MING-CHAU CHANG ${ }^{2,4,5}$ and WEI-MING CHEN ${ }^{2,4,5}$ \\ ${ }^{1}$ Division of Medical Oncology, Center for Immuno-Oncology, Department of Oncology; \\ ${ }^{2}$ Therapeutical and Research Center of Musculoskeletal Tumor; ${ }^{3}$ Division of Pediatric Hematology and Oncology, \\ Department of Pediatrics; ${ }^{4}$ Department of Orthopedics and Traumatology, Taipei Veterans General Hospital, \\ Taipei 11217; ${ }^{5}$ National Yang-Ming University School of Medicine, Taipei 11221, Taiwan, R.O.C.
}

Received November 6, 2017; Accepted July 23, 2019

DOI: 10.3892/ijo.2019.4861

\begin{abstract}
Liposarcoma (LPS) is one of the most frequently reported type of soft-tissue sarcoma (STS). Well-differentiated (WD) LPS and dedifferentiated (DD) LPS are the two most common subtypes. Chemotherapy has been considered to be ineffective in LPS, and novel treatment agents are thus necessary. In this study, we reanalyzed two published microarray data sets of LPS. By comparing the top 50 upregulated genes in DD LPS in both sets of data, we identified 12 overlapping genes. Of note, the top five gene sets enriched in DD LPS in both sets of data were involved in cell cycle regulation. Among the 12 overlapping genes, aurora kinase A (AURKA) is a well-known gene involved in cell cycle regulation; we thus further investigated this gene. AURKA was significantly upregulated in DD LPS, compared with WD LPS. Among 40 cases of DD LPS in GSE30929, patients with high AURKA expression in tumors had significantly worse distant recurrence-free survival than those with low expression. In an in vitro model, MLN8237, an AURKA inhibitor, could inhibit AURKA in LPS cell lines with a resultant G2/M arrest. MLN8237 was also reported to exert a cytotoxic effect by inducing apoptosis in LPS cell lines. Furthermore, except for cisplatin, MLN8237 had a significantly synergistic effect with chemotherapy agents against LPS. MLN8237 induced cellular senescence in LPS cell lines with increased expression of DcR2, a senescence biomarker, and upregulated expression of cytokines associated with the senescence-associated secretory phenotype, including interleukin (IL)-1 $\alpha$, IL-6 and IL-8. Our study identified AURKA
\end{abstract}

Correspondence to: Dr Chueh-Chuan Yen, Division of Medical Oncology, Center for Immuno-Oncology, Department of Oncology, Taipei Veterans General Hospital, 201, Sec 2, Shih-Pai Road, Taipei 112, Taiwan, R.O.C.

E-mail: ccyen@vghtpe.gov.tw

Key words: aurora kinase A, cellular senescence, liposarcoma, MLN8237 as a potential biomarker for predicting poor prognosis in LPS. The findings of the present study suggested the potential of AURKA as a therapeutic target in LPS cell line models, while the novel combination of AURKA inhibitors and chemotherapy requires further investigation.

\section{Introduction}

Soft-tissue sarcomas (STSs) are a group of heterogeneous tumors that account for $<1 \%$ of all cancers (1). Therefore, identifying potential targets in STSs is challenging. The most successful example is the identification of the activated mutation of KIT/platelet-derived growth factor receptor A (PDGFRA) in gastrointestinal stromal tumors (GISTs). Tyrosine kinase inhibitors against activated KIT/PDGFRA have been successfully developed for GISTs (2-4). Other examples include rare tumors such as dermatofibrosarcoma protuberans (DFSPs) (5) or inflammatory myofibroblastic tumor (6). For most other types of sarcomas, no satisfactory target therapies are available for clinical use.

Expression profiling is one of the most commonly used methods for exploring novel targets and biomarkers. Nonetheless, identifying treatment targets in sarcoma is difficult due to its complex genomic background. However, by using genomic and expression profiling in 183 STSs, Chibon et al (7) established a prognostic gene expression signature, complexity index in sarcomas (CINSARC), comprising 67 genes related to mitosis and chromosome management. CINSARC could predict the metastasis outcome in an independent validation set of 127 sarcomas (7). By reanalyzing a data set of GISTs, our group also identified aurora kinase A (AURKA), along with other genes involving cell cycle and mitosis, as prognostic factors for recurrence. AURKA could also act as a potential treatment target $(8,9)$. Therefore, through the use of expression profiling analysis, identifying potential biomarkers and targets in sarcoma is possible.

Liposarcoma (LPS) is one of the most frequently reported cancer of the STSs $(10,11)$. Chemotherapy is not effective in LPS (12), and at present, no satisfactory target agents against the disease are available. Expression profile studies revealed 
the activation of the cell cycle and checkpoint pathways in LPS, and provided several possible novel therapeutic strategies (13). A cyclin dependent kinase (CDK)4/6 inhibitor was used in the treatment of LPS (14).

In this study, we reanalyzed two published microarray data sets of well-differentiated (WD) and dedifferentiated (DD) LPS to identify potential biomarkers or targets in LPS. We determined that AURKA could be a potential biomarker for predicting poor prognosis in LPS. Subsequently, we identified AURKA as a potential therapeutic target for the treatment of LPS.

\section{Materials and methods}

Bioinformatics analysis. The microarray and limited clinicopathological data from the Gene Expression Omnibus data set GSE30929 for LPS, a raw data set from the study of Gobble et al (15), were obtained from the National Center for Biotechnology Information website (https://www.ncbi.nlm. nih.gov/geo/query/acc.cgi?acc=GSE30929). Only data of WD LPS and DD LPS were used for analysis. Gene expression data from GSE30929 were normalized using dChip $(16,17)$ and filtered with a max $/ \mathrm{min}$ threshold of $\geq 5$, after which they were exported for further analysis. For another data set from the study of Singer et al (13), including 12 cases of DD LPS and 18 cases of WD LPS, only certain genes were available from www.cbio.mskcc.org/Public/Liposarcoma. Thus, no further filtering process was conducted. Both data sets are the Affymetrix U133A platform (Thermo Fisher Scientific, Inc.). In order to identify genes showing statistically significant, concordant differences of expressions between two biological states (e.g. phenotypes), Gene Set Enrichment Analysis (GSEA), a method developed by the Broad Institute, was performed using software downloaded from http://www. broadinstitute.org/gsea/index.jsp $(18,19)$. The expression levels of individual genes were obtained using Z-score transformation, and the differences between different subtypes were then compared using a t-test. In the GSE30929 data set, data regarding patients' endpoint (distant recurrence) and follow-up time were obtained (ftp://ftp.ncbi.nlm.nih.gov/geo/series/ GSE30nnn/GSE30929/matrix/). Therefore, distant recurrence-free survival (DRFS) was estimated via Kaplan-Meier analysis, and a log-rank test was used to compare the survival curves between groups.

Cell lines and reagents. The LPS cell lines, including LPS853 was kindly provided by Dr Fletcher JA (Department of Pathology, Brigham and Women's Hospital), while NDDLS-1 was kindly provided by Dr Ariizumi (Division of Orthopedic Surgery, Niigata University Graduate School of Medical and Dental Sciences). LPS853 cells were maintained in RPMI medium with $15 \%$ fetal bovine serum (HyClone; GE Healthcare Life Sciences), $100 \mu \mathrm{g} / \mathrm{ml}$ penicillin streptomycin (HyClone; GE Healthcare Life Sciences) and $2 \mathrm{mM}$ L-glutamine solution (HyClone; GE Healthcare Life Sciences); NDDLS-1 cells were maintained in RPMI medium with $10 \%$ fetal bovine serum (HyClone; GE Healthcare Life Sciences), $100 \mu \mathrm{g} / \mathrm{ml}$ penicillin streptomycin (HyClone; GE Healthcare Life Sciences), 2 mM L-Glutamine solution (HyClone; GE Healthcare Life Sciences) and $60 \mu \mathrm{g} / \mathrm{ml}$ kanamycin (Thermo Fisher Scientific,
Inc.). MLN8237, an AURKA-selective inhibitor, and chemotherapeutic agents doxorubicin, topotecan, cisplatin and taxol were purchased from Selleck Chemicals. For MLN8237, concentrations of $0,0.02,0.05,0.1,0.5$ and $1 \mu \mathrm{M}$ were used to evaluate mitotic inhibition, the cell cycle and cytotoxic effects; concentrations of $0,0.4,0.8,1.2,1.6$ and $2 \mu \mathrm{M}$ were used for the exploring synergistic effects with chemotherapeutic agents. The concentrations of chemotherapeutic agents were listed as follows: Cisplatin 0, 4, 8, 12, 16, $20 \mu \mathrm{M}$; topotecan $0,4,8,12,16,20 \mu \mathrm{M}$; doxorubicin $0,0.1,0.2,0.3,0.4,0.5 \mu \mathrm{M}$; and taxol $0,6,12,18,24,30 \mu \mathrm{M}$. Nocodazole was purchased from Sigma-Aldrich (M1404-2MG; Merck KGaA). $0 \mu \mathrm{M}$ inhibitor served as the control. The following antibodies were used for immunoblotting: $\beta$-Actin (cat. no. ab6276-100; 1:10,000; Abcam); Aurora A (cat. no. 3092; 1:1,000; Cell Signaling Technology, Inc.); anti-phosphorylated-Aurora A (Thr288; p-Aurora A; cat. no. 3079; 1:1,000; Cell Signaling Technology, Inc.); poly-(ADP-ribose) polymerase (PARP; cat. no. 9542; 1:1,000; Cell Signaling Technology, Inc.), Histone H3 (HisH3; cat. no. 9715; 1:1,000; Cell Signaling Technology, Inc.), anti-phosphorylated (p)HisH3 (Ser10; pHisH3; cat. no. 9701; 1:2,000; Cell Signaling Technology, Inc.), p70S6 kinase (cat. no. 9202; 1:1,000; Cell Signaling Technology, Inc.) and pp70S6 kinase (cat. no. 9205; 1:500; Cell Signaling Technology, Inc.). The secondary antibodies used were horse anti-mouse IgG (cat. no. 7076; 1:3,000) and goat anti-rabbit IgG (cat. no. 7074; 1:3,000), both from Cell Signaling Technology.

Immunoblotting. Immunoblotting was performed as previously described (20). In brief, cultured monolayer cells were rinsed in PBS and scraped into lysis buffer (RIPA Lysis and Extraction Buffer; cat. no. 89901; Thermo Fisher Scientific, Inc.) containing protease and a phosphatase inhibitor cocktail (1:100 dilution; Thermo Fisher Scientific, Inc.). Lysates were first incubated for $30 \mathrm{~min}$ at $4^{\circ} \mathrm{C}$ and then centrifuged for $30 \mathrm{~min}$ at $16,000 \mathrm{xg}$ at $4^{\circ} \mathrm{C}$. A Pierce BCA Protein Assay Kit (Thermo Fisher Scientific, Inc.) was employed to determine protein concentrations. Protein extracts (20-50 $\mu \mathrm{g}$ per lane) were then electrophoretically separated on SDS-PAGE (8-12\% depending on the molecular weights of proteins), transferred to polyvinylidene difluoride membranes (PerkinElmer, Inc.), and immunoblotted with specific antibodies. For primary antibodies, the sample was incubated at $4^{\circ} \mathrm{C}$ overnight; for secondary antibody, the sample was incubated at room temperature for $1 \mathrm{~h}$. Immunoreactive bands were detected through enhanced chemiluminescence (EMD Millipore) and exposed to X-ray films. Protein expression was quantified using ImageJ version 1.51j8 (National Institutes of Health).

Cytotoxicity assay. TACS ${ }^{\mathrm{TM}}$ MTT assay (R\&D Systems) was used for the cell cytotoxicity assay. In brief, $2,000-20,000$ cells per $100 \mu \mathrm{l}$ per well were seeded in 96 -well plates at $37^{\circ} \mathrm{C}$ overnight. The following day, reagents at different concentrations were added in triplicate. The plates were subsequently incubated for the $72 \mathrm{~h}$ at $37^{\circ} \mathrm{C}$, incubated with $10 \mu \mathrm{l}$ MTT reagent, and then incubated for a further $4 \mathrm{~h}$ at $37^{\circ} \mathrm{C}$. Dimethyl sulfoxide $100 \mu \mathrm{l} /$ well was added and mixed thoroughly to dissolve the blue crystals. A Vmax microplate reader (Molecular Devices, LLC) at wavelengths of $570 \mathrm{~nm}$ 
(test) and $650 \mathrm{~nm}$ was used to measure the absorbance. Cell survival was calculated through the following equation: \% Survival= $($ mean experimental absorbance/mean control absorbance) x100 (21).

The synergistic effect of the applied drug combination was measured through a combination index (CI), which was calculated using CalcuSyn software 2.1 (Premier Biosoft International) (22). CI $>1$ was defined as antagonism, $\mathrm{CI}=1$ as additivity, and $\mathrm{CI}<1$ as synergy; the experiment was performed in triplicate.

A trypan blue exclusion assay (23) was also employed for exploring the cytotoxic effects of MLN8237. LPS cells were plated at $5 \times 10^{4}$ cells/well in 24-well plates; then, different concentrations of MLN8237 was added to each well the next day, and the plates were incubated at $37^{\circ} \mathrm{C}$ for $72 \mathrm{~h}$. Subsequently, the cells were trypsinized and mixed with trypan blue at room temperature and observed immediately. Viable cells, recognized as cells that did not absorb trypan blue, were counted using a light microscope (magnification, $\mathrm{x} 100$; cells were counted in the large, central gridded square at $1 \mathrm{~mm}^{2}$, then multiplied by $1 \times 10^{4}$ to estimate the number of cells per $\mathrm{ml}$ ). All experiments were performed in triplicate.

Apoptosis assessment through Annexin V staining. After drug treatment, cells $\left(1 \times 10^{5}\right.$ cells/well $)$ were washed with $1 \mathrm{X}$ PBS once and resuspended in $100 \mu \mathrm{l}$ staining solution (containing Annexin V fluorescein isothiocyanate (FITC) and propidium iodide in HEPES buffer, BD Pharmingen; BD Biosciences). The cells were then incubated at room temperature for $15 \mathrm{~min}$ and then diluted in $1 \mathrm{X}$ Annexin V-binding buffer (BD Biosciences). The percentages of apoptotic cells were then measured using flow cytometry (BD FACSCanto II, BD Biosciences; operation software: BD FACSDiva Software v8.0.2; analysis software: FlowJo 7.6).

Small interfering RNA (siRNA)-mediated knockdown (KD) of $A U R K A$. For AURKA KD experiment, $5 \times 10^{5}$ of LPS853 cells were transfected with either AURKA siRNA or non-targeting control pool using ON-TARGETplus system (GE Healthcare Dharmacon, Inc.) according to manufacturer's protocols (Target Sequence: UCGAAGAGAGUUAUUCAUA, CGG UAGGCCUGAUUGGGUU, UUCUUAGACUGUAUGGUU A, AAUAGGAACACGUGCUCUA; $10 \mu \mathrm{M}$ ); DharmaFECT 1 Transfection Reagent (cat. no. T-2001-03; GE Healthcare Dharmacon, Inc.) was employed for transfection. The cells were incubated for 48,72 and $96 \mathrm{~h}$ along at $37^{\circ} \mathrm{C}$ with respective controls, and number of viable cells was measured using trypan blue exclusion assay, as described above. The remaining cells then were lysed and the KD efficiency of AURKA, as well as the protein levels of PARP were confirmed by western blotting, as aforementioned.

Cell cycle analysis. Cell cycle analysis was performed using flow cytometry, as previously described (9). After being trypsinized and washed twice with PBS, cells ( $1 \times 10^{5}$ cells $\left./ \mathrm{ml}\right)$ were fixed in $99 \%$ ethanol at $-20^{\circ} \mathrm{C}$ overnight. The following day, the fixed cells were first washed twice with cold PBS, suspended in $420 \mu \mathrm{l}$ PBS, added to $50 \mu \mathrm{l}$ of $10 \mathrm{mg} / \mathrm{ml}$ RNase A (Sigma-Aldrich; Merck KGaA), and agitated at $37^{\circ} \mathrm{C}$ for $15 \mathrm{~min}$. The cells were then maintained at room temperature for $1 \mathrm{~h}$ following the addition of $20 \mu \mathrm{l}$ propidium iodide (0.2 $\mathrm{mg} / \mathrm{ml})$. Subsequently, flow cytometry was conducted using BD FACSCalibur (BD Biosciences) for relative DNA content based on red fluorescence levels. FACSDiva Software v8.0.2 was used to calculate the percentages of the cells in the different phases of the mitotic cell cycle.

Senescence-associated $\beta$-galactosidase (SA- $\beta$-gal) assay. SA- $\beta$-gal activity was detected using the Cellular Senescence Assay Kit (EMD Millipore), as described in the manufacturer's instructions. After being treated with MLN8237 at $37^{\circ} \mathrm{C}$ for $72 \mathrm{~h}$, adherent LPS853 cells were fixed with $1 \mathrm{X}$ fix solution at room temperature, incubate for $10 \mathrm{~min}$, and stained with $\mathrm{X}$-gal in a staining solution at $\mathrm{pH} 6.0$ at $37^{\circ} \mathrm{C}$ for $5 \mathrm{~h}$. The cells were washed twice with $1 \mathrm{X}$ PBS. The percentage of SA- $\beta$-gal-positive cells (the number of positive cells relative to the total number of cells) was quantified by counting 100 cells in three randomly selected fields per dish with an OLYMPUS IX51 microscope (brightfield with phase contrast; magnification, $\mathrm{x} 200)$.

Decoy receptor 2 (DcR2) expression analysis via flow cytometry. The expression of DcR 2 was detected using flow cytometry $\left(1 \times 10^{5}\right.$ cells $\left./ 100 \mu \mathrm{l}\right)$. LPS853 cells were first treated with MLN8237 at $37^{\circ} \mathrm{C}$ for $72 \mathrm{~h}$, washed twice with 1X PBS, and incubated with Alexa Fluor ${ }^{\circledR}$ 488-labeled anti-DcR2 (R\&D Systems, Inc.) on a shaker at room temperature for $30 \mathrm{~min}$. Cells were washed twice with $1 \mathrm{X}$ PBS and then resuspended in $1 \mathrm{X}$ PBS, the mean of the fluorescence intensity on the cell surface was measured by flow cytometry using FACSCalibur (BD Biosciences).

Analysis of interleukin (IL)-1 $\alpha, I L-6$ and IL-8 expression using reverse transcription-quantitative transcriptase-polymerase chain reaction (RT-qPCR). TRIzol ${ }^{\circledR}$ Reagent (Thermo Fisher Scientific, Inc.) was used for RNA extraction from the cell lines, in accordance with the manufacturer's protocols. The SuperScript ${ }^{\circledR}$ III First-Strand Synthesis System (Invitrogen Thermo Fisher Scientific, Inc.) was used for reverse transcription with $1 \mu \mathrm{g}$ RNA $\left(25^{\circ} \mathrm{C}\right.$ for $10 \mathrm{~min}, 50^{\circ} \mathrm{C}$ for $50 \mathrm{~min}, 85^{\circ} \mathrm{C}$ for $5 \mathrm{~min}$, hold at $4^{\circ} \mathrm{C}$ ). The copy number for IL-1 $\alpha$, IL- 6 , IL- 8 , and glyceraldehyde 3-phosphate dehydrogenase (GAPDH) mRNA was measured using RT-qPCR with Maxima SYBR ${ }^{\circledR}$ Green/ ROX qPCR Master Mix (Thermo Fisher Scientific, Inc.) and a LightCycler ${ }^{\circledR} 480$ System (Roche Diagnostics). The primer sequences used in the reaction were as follows: IL-1 $\alpha$ (forward), 5'-CCGTGAGTTTCCCAGAAGAA-3'; IL-1 $\alpha$ (reverse), 5'-ACTGCCCAAGATGAAGACCA-3'; IL-6 (forward), 5'-CATTTGTGGTTGGGTCAGG-3'; IL-6 (reverse), 5'-AGT GAGGAACAAGCCAGAGC-3'; IL-8 (forward) 5'-CAAGAG CCAGGAAGAAACCA-3'; IL-8 (reverse) 5'-AGCACTCCT TGGCAAAACTG-3'; GAPDH (forward) 5'-GCCAAGGTC ATCCATGACAACT-3'; GAPDH (reverse), 5'-GAGGGGCCA TCCACAGTCTT-3' (24). The qPCR thermocycling conditions were as follows: $95^{\circ} \mathrm{C}$ for $5 \mathrm{~min}$ and then 45 cycles of $95^{\circ} \mathrm{C}$ for $30 \mathrm{sec}, 55^{\circ} \mathrm{C}$ for $30 \mathrm{sec}$, and $72^{\circ} \mathrm{C}$ for $40 \mathrm{sec}$. The gene expression levels were calculated as described previously (25).

Statistical and survival analysis. SPSS Statistics 22 (IBM Corp.) was used for statistical analysis. As aforementioned, 
Table I. Top 5 gene sets enriched in dedifferentiated liposarcoma in GSE30929.

\begin{tabular}{lccc}
\hline NAME & NES & Nominal P-value & FDR q-value \\
\hline MITOSIS & 2.086395 & 0.002008 & 0.032142 \\
M_PHASE_OF_MITOTIC_CELL_CYCLE & 2.078066 & 0.002004 & 0.019095 \\
SPINDLE & 2.052216 & $<0.0001$ & 0.019665 \\
M_PHASE & 2.039629 & $<0.0001$ & 0.016213 \\
CELL_CYCLE_CHECKPOINT_GO_0000075 & 2.036067 & 0.004124 & 0.013608
\end{tabular}

GO, Gene Ontology; NES, normalized enrichment score; FDR, false discovery rate.

Table II. Top 5 gene sets enriched in dedifferentiated liposarcoma the data of Singer et al (13).

\begin{tabular}{lcrr}
\hline NAME & NES & Nominal P-value & FDR q-value \\
\hline MITOTIC_CELL_CYCLE & 1.574733 & 0.016393 & 0.293481 \\
CELL_CYCLE_PROCESS & 1.567766 & 0.024691 & 0.154675 \\
CELL_CYCLE_PHASE & 1.547144 & 0.034908 & 0.132447 \\
CELL_CYCLE_GO_0007049 & 1.533873 & 0.055215 & 0.112444 \\
REGULATION_OF_CELL_CYCLE & 1.312828 & 0.179167 & 0.477817 \\
\hline
\end{tabular}

GO, Gene Ontology; NES, normalized enrichment score; FDR, false discovery rate.

survival analysis was estimated using the Kaplan-Meier method, and the log-rank test was conducted for survival curve comparison. A Student's t-test was used for comparing the difference of the expression levels of AURKA between two subtypes of LPS, and the expression levels of p-Aurora A in LPS cell lines before and after drug treatment. The difference in expression levels of pHisH3 (assessed by western blotting), the percentage of G2/M content (assessed by flow cytometry), percentage of cell survival (assessed by MTT assay), number of viable cells (assessed by trypan blue exclusion assay), percentage of apoptotic cells (assessed by apoptosis assay), and the senescence-related markers (SA- $\beta$-gal staining, flow cytometry of DcR2, and RT-qPCR of IL-1 $\alpha$, IL-6, and IL-8) between control and treated (all in triplicate) LPS cell lines were compared using one-way ANOVA, and Bonferroni test was used as post hoc test. Data was presented as the mean \pm standard deviation; $\mathrm{P}<0.05$ was considered to indicate a statistically significant difference.

\section{Results}

AURKA is significantly upregulated in DD LPS compared with WD LPS, and DD LPS patients with high AURKA expression had significantly worse DRFS than those with low expression. A total of 92 arrays from GSE30929 were obtained, involving 40 cases of DD LPS and 52 cases of WD LPS (15). Microarray data were first normalized through dChip, and a total of 17,089 probes were obtained after filtering with a max/min threshold of $\geq 5$. The expression values of LPS from GSE30929 and Singer et al (13) were then analyzed using GSEA software. Subsequently, a heatmap was generated from GESA using the top 50 genes of each phenotype (DD vs. WD LPS) in each set of tumors (Fig. S1). By comparing the top 50 genes that were upregulated in DD LPS in both sets of data, we identified 12 overlapping genes, namely nuclear and spindle associated protein 1, maternal embryonic leucine zipper kinase, AURKA, BAG family molecular chaperone regulator 2, CDC28 protein kinase regulatory subunit 2 , kinesin family member 11 , DNA topoisomerase II, Rac GTPase-activating protein 1, abnormal spindle-like microencephaly-associated protein, ribonucloside-disphosphate reductase subunit M2, retinoic acid induced 14 and ubiquitin-conjugating enzyme E2 S.

Notably, the top five gene sets enriched in DD LPS in both sets of data were all involved in cell cycle regulation (Tables I and II). Among the 12 overlapping genes, AURKA is a well-known gene involved in cell cycle regulation (26). Thus, we selected this gene for further analysis. As presented in Fig. 1, in both sets of tumors, AURKA was significantly upregulated in DD LPS in comparison with WD LPS. Survival data are available in GSE30929. We then compared the DRFS data of cases with low AURKA expression (Z-score <0) vs. those with high AURKA expression in DD LPS. As shown in Fig. 1C, among the 40 cases of DD LPS, patients with high expression of AURKA in tumors $(n=27)$ had significantly worse DRFS than those with low expression $(n=13)$.

AURKA-KD decreases the number of viable cells and induces apoptosis in LPS cell lines. AURKA-KD was performed in LPS853 cells using siRNA against AURKA with appropriate controls. As presented in Fig. 2A, silencing of AURKA was demonstrated at the protein level using anti-AURKA antibody. AURKA-KD was also associated with increased cleavage form of PARP, indicating an apoptosis-inducing effect (Fig. 2A). Furthermore, compared with the control, AURKA-KD signifi- 

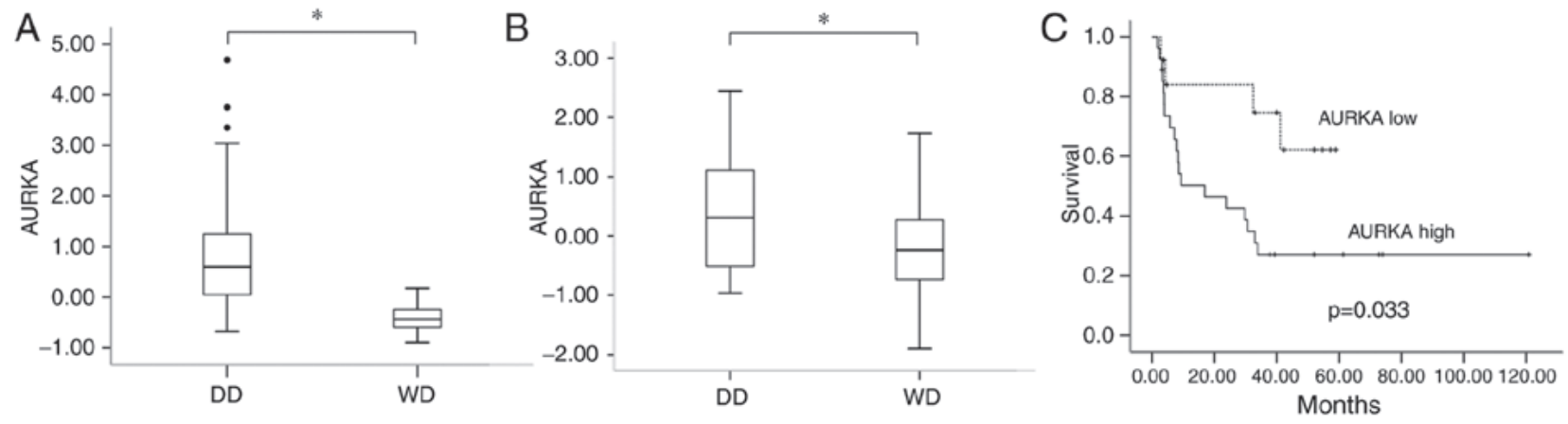

Figure 1. AURKA is significantly upregulated in DD LPS in comparison with WD LPS. (A) Data set from GSE30929; (B) data set from the study of Singer et al ${ }^{*} \mathrm{P}<0.05$. (C) Patients with DD LPS from GSE30929 with high AURKA expression in tumors $(\mathrm{n}=27)$ had significantly poorer distant recurrence-free survival than those with low AURKA expression ( $\mathrm{n}=13$ ). $\mathrm{P}<0.05$. AURKA, aurora kinase A; DD, dedifferentiated; LPS, liposarcoma; WD, well-differentiated.
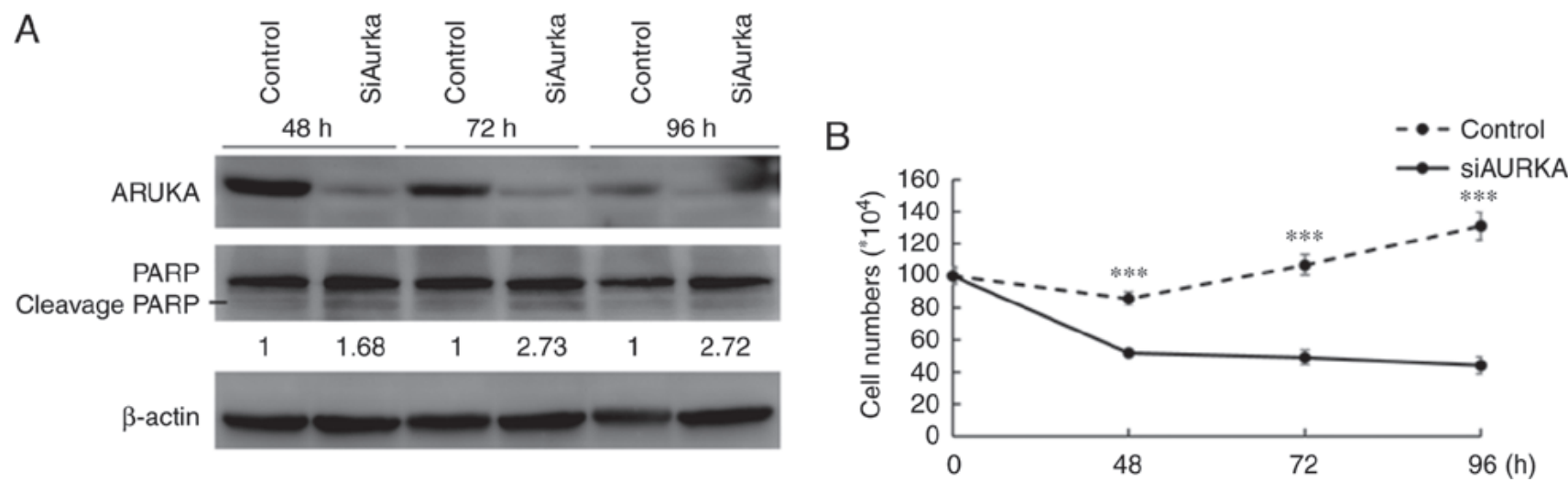

Figure 2. AURKA-KD decreases cell viability. (A) Western blotting of LPS853 following transfection with siAURKA or control demonstrated a KD effect of AURKA expression, which was accompanied with increased cleavage of PARP. (B) AURKA KD decreased number of viable cells (as determined by a trypan blue exclusion assay) in LPS853 cells. ${ }^{* * *} \mathrm{P}<0.001$ vs. control. AURKA, aurora kinase A; KD, knockdown; PARP, poly-(ADP-ribose) polymerase; si, small interfering RNA.

cantly decreased number of viable cells (as determined by a trypan blue exclusion assay) in LPS853 cells (Fig. 2B). The results indicated that AURKA could act as a potential therapeutic target in LPS cells.

MLN8237 inhibits AURKA and induces G2/M arrest in $L P S$ cell lines. We used an in vitro model to determine the potential of AURKA as a therapeutic target in LPS. MLN8237 is a potent inhibitor of AURKA that reduces the activity of AURKA in a variety of cancers $(9,27,28)$. We examined whether MLN8237 inhibits AURKA phosphorylation and induces mitotic arrest in LPS cells. As shown in Fig. 3, immunoblotting revealed significantly decreased AURKA phosphorylation levels in nocodazole-stimulated and MLN8237-treated (treated with nocodazole $400 \mathrm{nM}$ for $8 \mathrm{~h}$ then added MLN8237 for $4 \mathrm{~h}$ ) LPS853 and NDDLS-1 compared with the control ( $0 \mu \mathrm{M}$ inhibitor) (Fig. $3 \mathrm{~A}$ and $\mathrm{B})$. In addition, the levels of $\mathrm{pHisH} 3$, an indicator of mitotic arrest, were significantly increased in both cell lines, in comparison with control, after treatment with MLN8237 at $0.5 \mu \mathrm{M}$ for $8 \mathrm{~h}$; LPS853 cells exhibited a significant increase in pHis 3 expression in response to $1 \mu \mathrm{M}$ MLN8237 (Fig. 3C). Flow cytometry analysis of DNA content in LPS853 and NDDLS-1 cells treated with MLN8237 demonstrated that this compound caused a significant accumulation of cells at
G2/M DNA content, in comparison with control, in the two LPS cell lines (Figs. 3D and S2). These studies indicated that MLN8237 could target AURKA and induce mitotic arrest in LPS cells.

MLN8237 exerts cytotoxic effects by inducing apoptosis in LPS cell lines. We examined whether MLN8237 could exhibit cytotoxic activity against LPS cell lines. MLN8237 exerted significant cytotoxic effects against NDDLS-1 and LPS853 cells as assessed through an MTT assay (Fig. 4A) or via a trypan blue exclusion assay (Fig. 4B). A significant induction of apoptosis in LPS cell lines was also detected by costaining with propidium iodide and FITC-labeled Annexin $\mathrm{V}$ (both early and late apoptotic cells are included as indicated by total cell number with positive Annexin V-FITC, Figs. 4C and S3).

Synergistic effects of combining MLN8237 and chemotherapeutic agents. As LPS exhibited some sensitivity to chemotherapy, we next explored the possible synergistic effects of treatment with both MLN8237 and chemotherapy. As presented in Figs. 5 and 6, except for cisplatin, MLN8237 exhibited significant synergistic effect (combination index $<1.0$ ) with all other chemotherapeutic agents against LPS cell lines LPS853 (Fig. 5) and NDDLS-1 (Fig. 6) at least at two different 
A

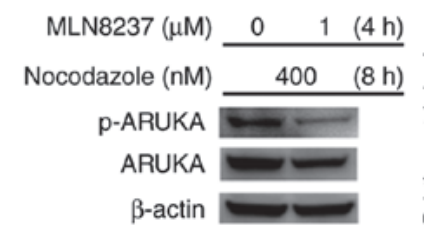

LPS853

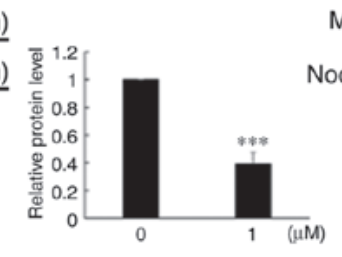

B

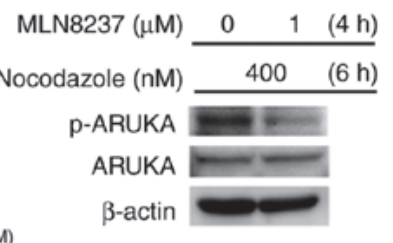

NDDLS-1

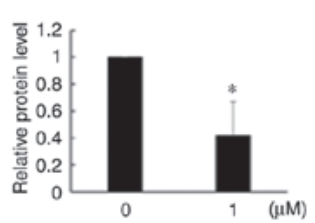

C LPS853

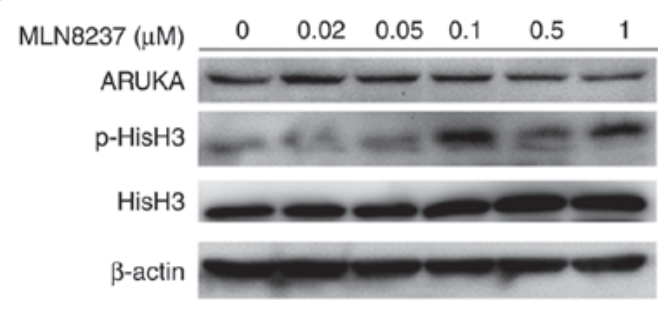

NDDLS-1

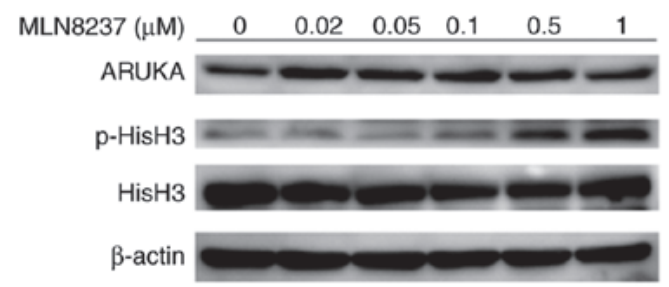

$\mathrm{D}$

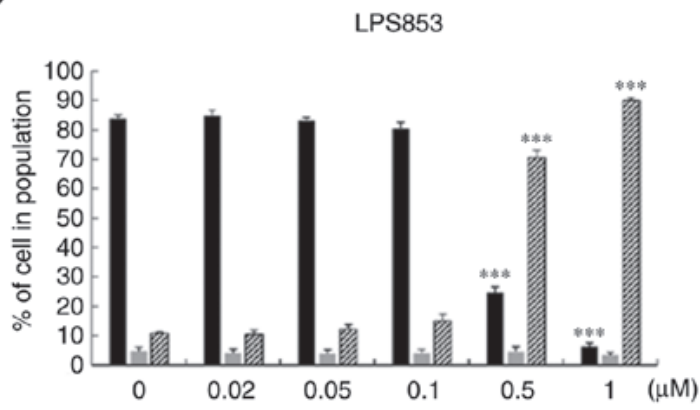

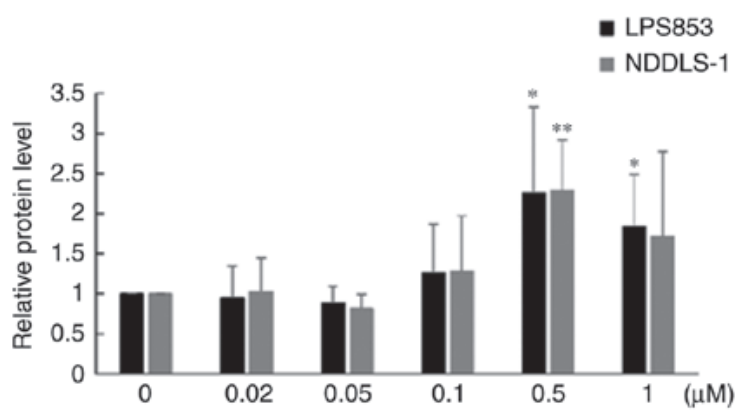

- $\mathrm{G} 1=\mathrm{S} \bullet \mathrm{G} 2 / \mathrm{M}$

NDDLS-1

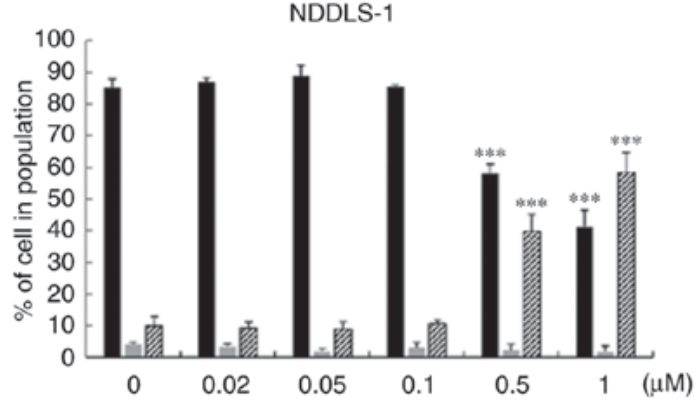

Figure 3. MLN8237 inhibits AURKA and induces mitotic arrest as well as G2/M arrest in LPS cell lines. Representative images of immunoblotting of nocodazole-stimulated, control or MLN8237-treated (A) LPS853 and (B) NDDLS-1 cells. Densitometry analysis revealed significantly decreased AURKA phosphorylation in both cell lines after MLN8237 treatment; experiments were performed in triplicate. (C) Representative images of immunoblotting of LPS853 and NDDLS-1 cells. Densitometry analysis demonstrated significantly increased pHisH3 levels in both cell lines after treatment with MLN8237 at $0.5 \mu \mathrm{M}$ for $8 \mathrm{~h} ; 1 \mu \mathrm{M}$ MLN8237 induced a significant increase in pHis3 expression within LPS853 cells. (D) Flow cytometry analysis of the DNA content in LPS853 and NDDLS-1 cells treated with MLN8237 for $72 \mathrm{~h}$ indicated a significant accumulation of LPS853 and NDDLS-1 cells in G2/M. ${ }^{*} \mathrm{P}<0.05,{ }^{* *} \mathrm{P}<0.01$, ${ }^{* * *} \mathrm{P}<0.001$ vs. control. AURKA, aurora kinase A; His3, histone 3; p, phosphorylated.

combination dose levels. These results indicate that MLN8237 can act synergistically with some chemotherapeutic agents, and provide future chances for combination therapy in LPS.

MLN8237 induces cellular senescence in LPS cell lines. AURKA inhibition may induce senescence in cells. To examine whether senescence occurred in LPS cells following treatment with MLN8237, a SA- $\beta$-gal assay was performed in LPS853 cells after being treated with MLN8237 for $72 \mathrm{~h}$. The size of LPS cells became larger and the shape went flatter after MLN8237 treatment. In addition, MLN8237 treatment significantly increased SA- $\beta$-gal activity in LPS cells compared with the control (Fig. 7A and B). The levels of pp70S6 kinase remained steady, indicating sustained mTOR activity (Fig. 7C). Furthermore, administration of MLN8237 significantly increased the expression of DcR2 (Fig. 7D), a well-known senescence biomarker, as well as the expression of IL-1 $\alpha$ (Fig. 7E), IL-6 (Fig. 7F) and IL-8 (Fig. 7G), cytokines associated with the senescence-associated secretory phenotype (SASP) (29), in LPS853 cells. Of note, the levels of IL-1 $\alpha$ and IL-8 did not significantly increase in response to $0.1 \mu \mathrm{M}$ MLN8237. Collectively, these results demonstrate that MLN8237 treatment induces senescence in LPS cells.

\section{Discussion}

In this study, we identified AURKA as a prognostic factor as well as potential therapeutic target for the treatment of 

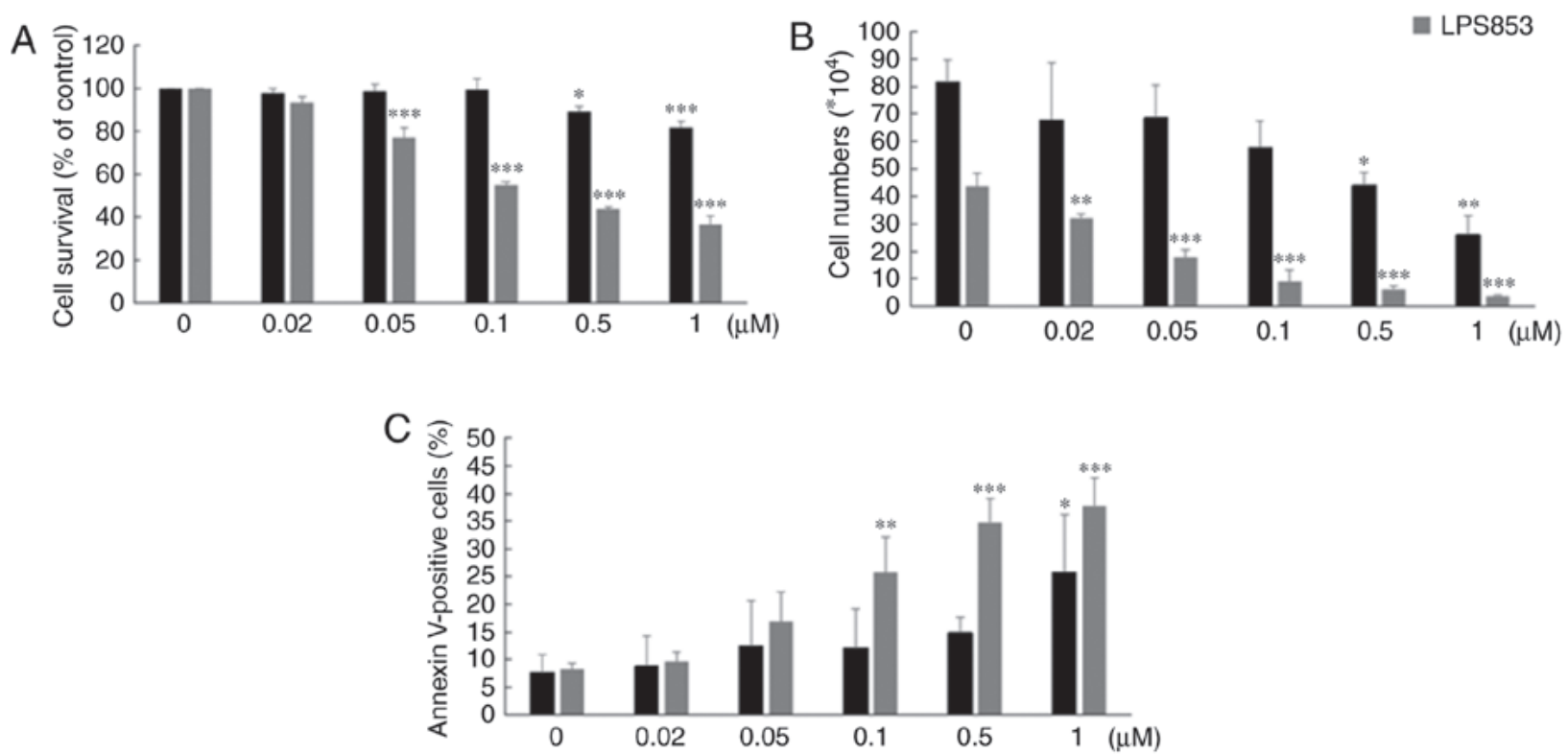

Figure 4. Growth inhibition and apoptosis in NDDLS-1 and LPS853 cell lines after treatment with MLN8237 of various concentrations for $72 \mathrm{~h}$. (A) The percentage of cell survival (measured with the TACS ${ }^{\text {TM }}$ MTT assay). (B) Number of viable cells (assessed by a trypan blue exclusion assay); (C) the percentage of apoptotic cells as determined by Annexin V-FITC/propidium iodide staining (both early and late apoptotic cells are included as indicated by Annexin V-FITC positive staining). All data are presented as the mean \pm standard deviation of three independent experiments. ${ }^{*} \mathrm{P}<0.05 ;{ }^{* *} \mathrm{P}<0.01,{ }^{* * * *} \mathrm{P}<0.001 \mathrm{vs}$. control. FITC, fluorescein isothiocyanate.

A

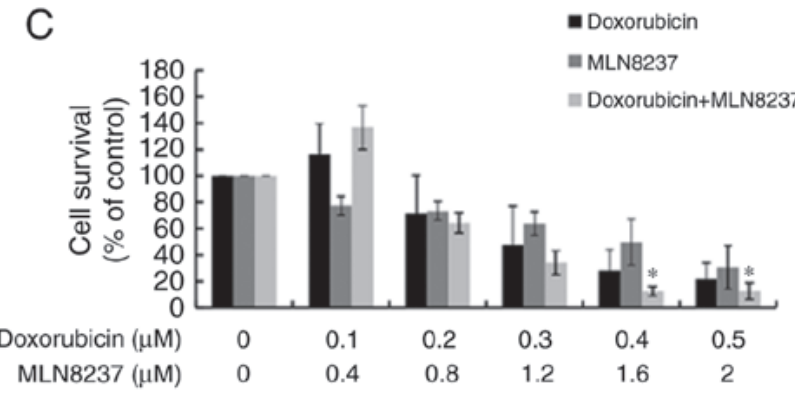

B

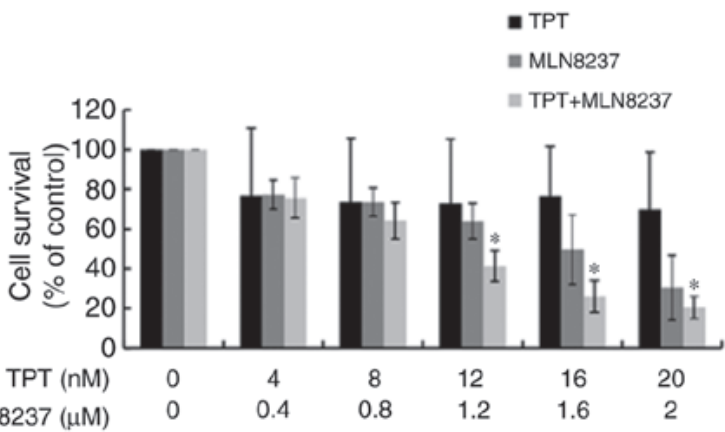

D

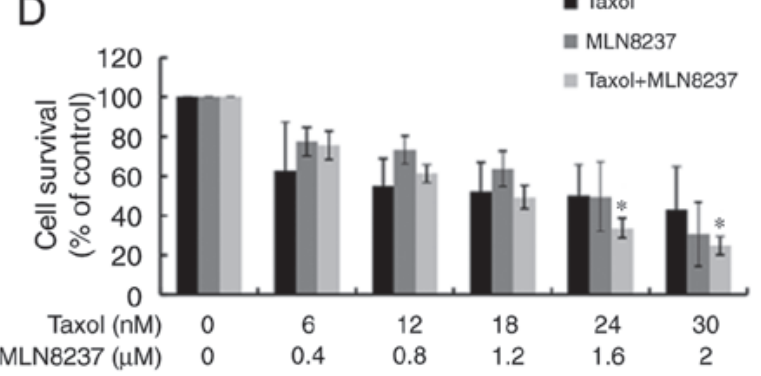

Figure 5. Synergistic effects of combining MLN8237 and chemotherapeutic agents on LPS853 cells. The cell survival of LPS853 cells treated with MLN8237, or chemotherapeutic agents, including (A) cisplatin, (B) TPT, (C) doxorubicin and (D) Taxol, or in combination for 72 h was measured via a TACS ${ }^{\mathrm{TM}}$ MTT assay (expressed as a percentage of cell survival under controlled culture conditions). All data are presented as the mean \pm standard deviation of three independent experiments. *, combination index $<1.0$ indicates a synergistic effect. TPT, topotecan.

LPS. An in vitro assay revealed that the AURKA inhibitor MLN8237 could inhibit cell growth and induce the apoptosis of LPS cell lines, and that this inhibitor exhibited a synergistic effect with several chemotherapeutic agents. MLN8237 was also observed to induce cellular senescence in LPS cell lines.
LPS has been demonstrated to account for $20-30 \%$ of STS cases $(10,11)$. Chemotherapy has been reported to be ineffective in LPS; however, recent clinical trials indicated that eribulin (clinical trial no. NCT01327885) $(30,31)$ and trabectedin (clinical trial no. NCT01343277) (32) benefited 
A

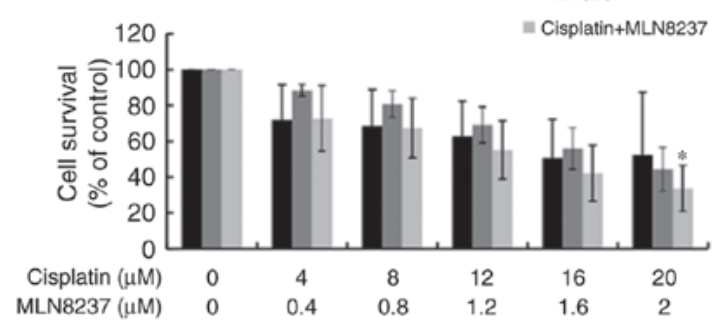

C
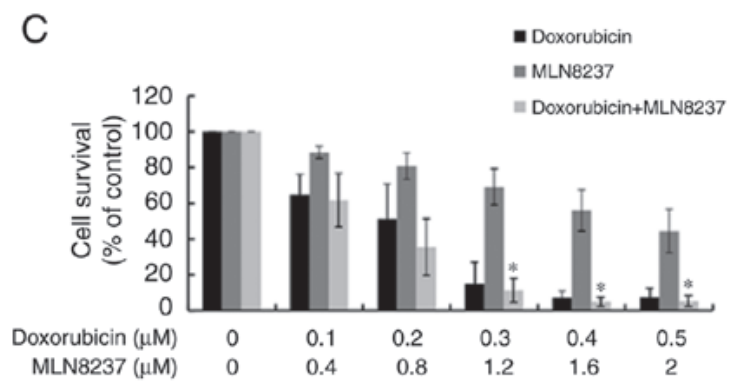

B
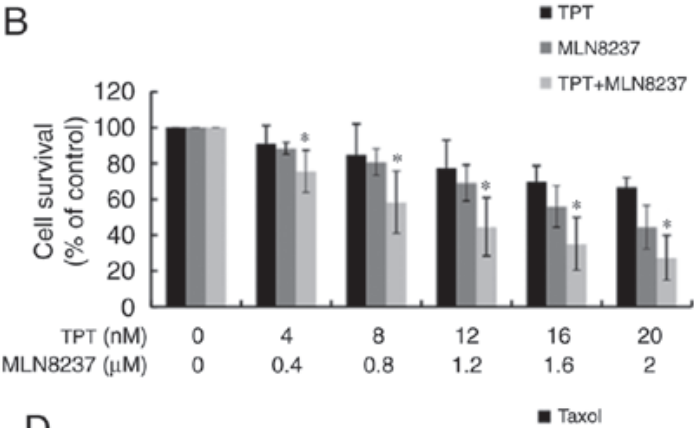

$\mathrm{D}$

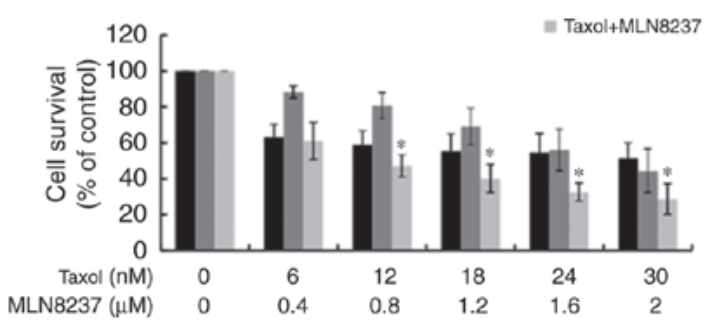

Figure 6. Synergistic effects of combining MLN8237 and chemotherapeutic agents on NDDLS-1 cells. The cell survival of NDDLS-1 cells treated with MLN8237 or chemotherapeutic agents, including (A) cisplatin, (B) TPT, (C) doxorubicin and (D) Taxol, or in combination for $72 \mathrm{~h}$ was measured via a TACS ${ }^{\mathrm{TM}}$ MTT assay (expressed as a percentage of cell survival under controlled culture conditions). All data are presented the mean \pm standard deviation of three independent experiments. *, combination index $<1.0$ indicates a synergistic effect. TPT, topotecan.

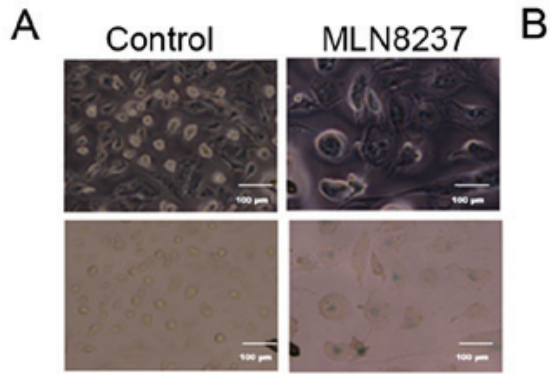

D

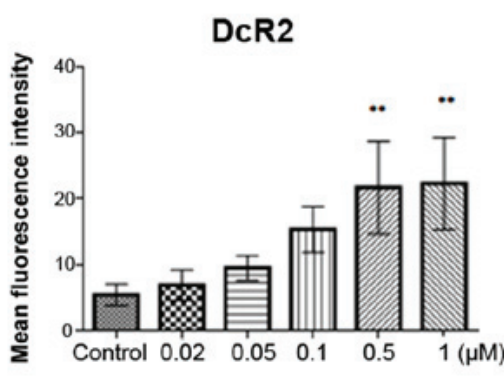

$\mathrm{F}$

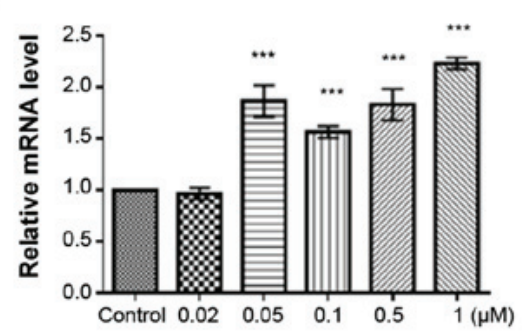

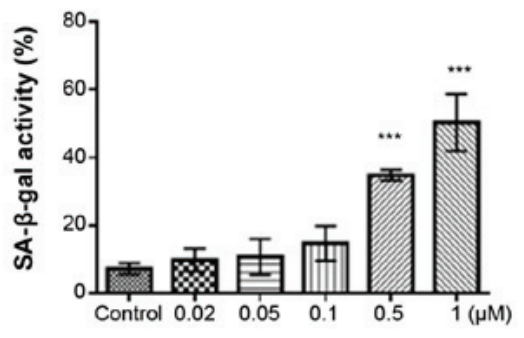

C

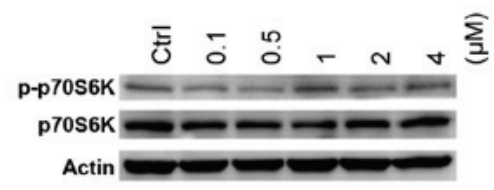

E

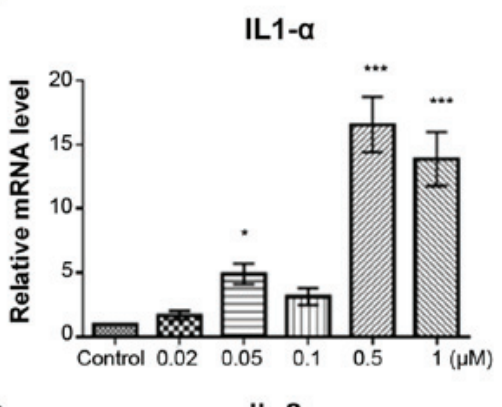

G

IL-8

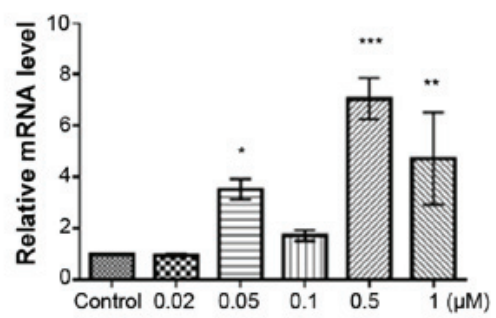

Figure 7. Inhibition of AURKA induces senescence in LPS853 cells. (A) The size of LPS cells became larger and the shape went flatter after MLN8237 treatment. The SA- $\beta$-gal activity was also increased (magnification x200, scale bar=100 $\mu \mathrm{m}$ ); (B) MLN8237 treatment significantly increased SA- $\beta$-gal activity in LPS cells; (C) the levels of p-p70S6K remained steady, indicating sustained mTOR activity; MLN8237 treatment increased the expression of (D) DcR2, a well-known senescence biomarker, and (E) (IL)-1 $\alpha$, (F) IL-6 and (G) IL-8, cytokines associated with the senescence-associated secretory phenotype, in LPS853 cells. All data are presented as the mean \pm standard deviation of three independent experiments. ${ }^{*} \mathrm{P}<0.05,{ }^{* *} \mathrm{P}<0.01,{ }^{* * * *} \mathrm{P}<0.001 \mathrm{vs}$. control. DcR2, Decoy receptor 2; IL, interleukin; p, phosphorylated; p70S6K, p70S6 kinase; SA- $\beta$-gal, senescence-associated $\beta$-galactosidase. 
survival in late-line therapy. Nevertheless, the response rate remains unsatisfactory. Our previous study reported that Akt1 overexpression could enhance adipogenesis and lead to lipoma formation in zebrafish (33). However, its role in the pathogenesis of LPS is still unclear.

WD and DD LPS, the two most common subtypes, shared common genomic changes with 12q13-15 amplification (34). Mouse double minute 2 and cyclin dependent kinase (CDK) 4 are two candidate genes within this region, and are routinely used as diagnostic markers for WD and DD LPS (35). In a phase II study of LPS (clinical trial no. NCT01209598), palbociclib, a CDK4/6 inhibitor, achieved a $66 \%$ (90\% confidence interval, 51-100\%) progression-free rate at 12 weeks, significantly exceeding the primary endpoint of the trial; nevertheless, there was only one partial response (14).

In the present study, by reanalyzing two published microarray data sets of LPS and comparing the top 50 genes that were overexpressed in DD LPS in both sets of data, we identified 12 overlapping genes. Furthermore, we discovered that the top five gene sets enriched in DD LPS in both sets of data were all involved in cell cycle regulation. AURKA, a well-known gene involved in cell cycle regulation, was then selected among the 12 overlapping genes. AURKA is one of the top three genes in the CINSARC list (7). Our group $(8,9)$ and Lagarde et al (36) have also identified AURKA as an independent prognostic factor in predicting GIST recurrence. Furthermore, the present study, AURKA was found to be overexpressed in DD LPS, compared with WD LPS, and could act as a prognostic factor in LPS.

In an in vitro study, MLN8237, an AURKA inhibitor, was proposed to inhibit AURKA in LPS cell lines with a resultant G2/M arrest. MLN8237 was observed to exert a cytotoxic effect by inducing apoptosis in LPS cell lines. These findings are consistent with that of our previous study of AURKA in GISTs (9). In a recent phase II study using MLN8237 (Alisertib) in treating 72 cases of sarcoma (clinical trial no. NCT01653028), a 73\% 12-week progression-free rate was achieved in 12 cases of LPS; however, none of them exhibited tumor response (37). Therefore, combining cell cycle inhibitors with other agents may be necessary to achieving improved cytotoxic effects on cancer cells. In the current study, MLN8237 was exhibited a significant synergistic effect with several of the chemotherapeutic agents tested against LPS cell lines. These results indicated a possibility of the combination of MLN8237 with chemotherapy for treating LPS.

Drugs targeting the cell cycle can cause therapy-induced senescence (TIS) (38). Senescent cells are permanently growth arrested in either G1 or G2/M stage of the cell cycle, but remain viable with sustained survival signaling (39). Of note, these cells can be visualized through a staining technique that employs a widely accepted and used marker, SA-b-gal activity (40).

In this study, we demonstrated that MLN8237 could induce several features of TIS in LPS, including the increased activity of SA- $\beta$-gal in cells with a flattened morphology and upregulated expression of DcR2, as well as the increased expression of proinflammatory cytokines IL-1 $\alpha$, IL- 6 and IL-8. These observations comprise called the SASP; prosurvival signaling was unaffected as suggested by the levels of pp70S6K. Similar findings have also been reported in our previous studies of the AURKA inhibitor MLN8237 in treating a GIST cell line (9) and of the polo-like kinase 1 inhibitor GSK461364 in treating an osteosarcoma cell line (20).

In summary, our study identified AURKA as a potential biomarker in predicting poor prognosis in LPS. We also reported the potential of AURKA as a therapeutic target in LPS cell line models. The novel combination of AURKA inhibitors with chemotherapy appears to be promising; however, further investigation is required.

\section{Acknowledgements}

This manuscript was edited by Wallace Academic Editing.

\section{Funding}

The present study was supported by grants from the National Science Council (grant nos. NSC 100-2314-B-075-081 and NSC 101-2314-B-075-029), Ministry of Science and Technology, Taiwan (grant nos. MOST 103-2314-B-075-066 and MOST 105-2314-B-075-059), and Taipei Veterans General Hospital (grant nos. V102E8-003, V103E8-001, V101C-133, V102C-034, V103C-188, V104C-099, V104E16-001-MY3-1, V104E16-001-MY3-2, V104D16-001-MY3-3, V105C-094, V106C-160, V107C-085, V107D32-001-MY2-2 and V108C-108) and from the Yen Tjing Ling Medical Foundation (grant nos. CI-100-19, CI-103-6 and CI-105-4) designated to Dr Chueh-Chuan Yen. This work was also supported by the Taiwan Clinical Oncology Research Foundation, and the Chong Hin Loon Memorial Cancer and Biotherapy Research Center of National Yang-Ming University.

\section{Availability of data and materials}

The datasets used and/or analyzed during the current study are available from the corresponding author on reasonable request.

\section{Authors' contributions}

CCY, SCC, GYH, PKW were responsible for the design and conception of the study; WYC, YCL, CHY, YCC, JYW were responsible for data acquisition and interpretation; MHY, YC, MCC and WMC were responsible for the data analysis and drafting the work. All authors have given final approval of the version to be published.

\section{Ethics approval and consent to participate}

Not applicable.

\section{Patient consent for publication}

Not applicable.

\section{Competing interests}

The authors declare that they have no competing interests. 


\section{References}

1. Jemal A, Siegel R, Xu J and Ward E: Cancer statistics, 2010. CA Cancer J Clin 60: 277-300, 2010.

2. Demetri GD, van Oosterom AT, Garrett CR, Blackstein ME, Shah MH, Verweij J, McArthur G, Judson IR, Heinrich MC, Morgan JA, et al: Efficacy and safety of sunitinib in patients with advanced gastrointestinal stromal tumour after failure of imatinib: A randomised controlled trial. Lancet 368: 1329-1338, 2006.

3. Blanke CD, Demetri GD, von Mehren M, Heinrich MC, Eisenberg B, Fletcher JA, Corless CL, Fletcher CD, Roberts PJ, Heinz D, et al: Long-term results from a randomized phase II trial of standard-versus higher-dose imatinib mesylate for patients with unresectable or metastatic gastrointestinal stromal tumors expressing KIT. J Clin Oncol 26: 620-625, 2008.

4. Demetri GD, Reichardt P, Kang YK, Blay JY, Rutkowski P, Gelderblom H, Hohenberger P, Leahy M, von Mehren M, Joensuu $\mathrm{H}$, et al: Efficacy and safety of regorafenib for advanced gastrointestinal stromal tumours after failure of imatinib and sunitinib (GRID): An international, multicentre, randomised, placebo-controlled, phase 3 trial. Lancet 381: 295-302, 2013.

5. McArthur GA, Demetri GD, van Oosterom A, Heinrich MC, Debiec-Rychter M, Corless CL, Nikolova Z, Dimitrijevic S and Fletcher JA: Molecular and clinical analysis of locally advanced dermatofibrosarcoma protuberans treated with imatinib: Imatinib Target Exploration Consortium Study B2225. J Clin Oncol 23: 866-873, 2005

6. Butrynski JE, D'Adamo DR, Hornick JL, Dal Cin P, Antonescu CR, Jhanwar SC, Ladanyi M, Capelletti M, Rodig SJ, Ramaiya N, et al: Crizotinib in ALK-rearranged inflammatory myofibroblastic tumor. N Engl J Med 363: 1727-1733, 2010.

7. Chibon F, Lagarde P, Salas S, Pérot G, Brouste V, Tirode F, Lucchesi C, de Reynies A, Kauffmann A, Bui B, et al: Validated prediction of clinical outcome in sarcomas and multiple types of cancer on the basis of a gene expression signature related to genome complexity. Nat Med 16: 781-787, 2010.

8. Yen CC, Yeh CN, Cheng CT, Jung SM, Huang SC, Chang TW, Jan YY, Tzeng CH, Chao TC, Chen YY, et al: Integrating bioinformatics and clinicopathological research of gastrointestinal stromal tumors: Identification of aurora kinase A as a poor risk marker. Ann Surg Oncol 19: 3491-3499, 2012.

9. Yeh CN, Yen CC, Chen YY, Cheng CT, Huang SC, Chang TW, Yao FY, Lin YC, Wen YS, Chiang KC, et al: Identification of aurora kinase $\mathrm{A}$ as an unfavorable prognostic factor and potential treatment target for metastatic gastrointestinal stromal tumors. Oncotarget 5: 4071-4086, 2014.

10. Hung GY, Yen CC, Horng JL, Liu CY, Chen WM, Chen TH and Liu CL: Incidences of primary soft tissue sarcoma diagnosed on extremities and trunk wall: A population-based study in Taiwan. Medicine (Baltimore) 94: e1696, 2015.

11. Liu CY, Yen CC, Chen WM, Chen TH, Chen PC, Wu HT, Shiau CY, Wu YC, Liu CL and Tzeng CH: Soft tissue sarcoma of extremities: The prognostic significance of adequate surgical margins in primary operation and reoperation after recurrence. Ann Surg Oncol 17: 2102-2111, 2010.

12. Italiano A, Toulmonde M, Cioffi A, Penel N, Isambert N, Bompas E, Duffaud F, Patrikidou A, Lortal B, Le Cesne A, et al: Advanced well-differentiated/dedifferentiated liposarcomas: Role of chemotherapy and survival. Ann Oncol 23: 1601-1607, 2012.

13. Singer S, Socci ND, Ambrosini G, Sambol E, Decarolis P, Wu Y, O'Connor R, Maki R, Viale A, Sander C, et al: Gene expression profiling of liposarcoma identifies distinct biological types/ subtypes and potential therapeutic targets in well-differentiated and dedifferentiated liposarcoma. Cancer Res 67: 6626-6636, 2007.

14. Dickson MA, Tap WD, Keohan ML, D'Angelo SP, Gounder MM, Antonescu CR, Landa J, Qin LX, Rathbone DD, Condy MM, et al: Phase II trial of the CDK4 inhibitor PD0332991 in patients with advanced CDK4-amplified well-differentiated or dedifferentiated liposarcoma. J Clin Oncol 31: 2024-2028, 2013.

15. Gobble RM, Qin LX, Brill ER, Angeles CV, Ugras S, O'Connor RB, Moraco NH, Decarolis PL, Antonescu C and Singer S: Expression profiling of liposarcoma yields a multigene predictor of patient outcome and identifies genes that contribute to liposarcomagenesis. Cancer Res 71: 2697-2705, 2011.

16. Li C and Hung Wong W: Model-based analysis of oligonucleotide arrays: Model validation, design issues and standard error application. Genome Biol 2: RESEARCH0032, 2001.
17. Li C and Wong WH: Model-based analysis of oligonucleotide arrays: Expression index computation and outlier detection. Proc Natl Acad Sci USA 98: 31-36, 2001.

18. Subramanian A, Tamayo P, Mootha VK, Mukherjee S, Ebert BL, Gillette MA, Paulovich A, Pomeroy SL, Golub TR, Lander ES and Mesirov JP: Gene set enrichment analysis: A knowledge-based approach for interpreting genome-wide expression profiles. Proc Natl Acad Sci USA 102: 15545-15550, 2005.

19. Mootha VK, Lindgren CM, Eriksson KF, Subramanian A, Sihag S, Lehar J, Puigserver P, Carlsson E, Ridderstrale M, Laurila E, et al: PGC-1alpha-responsive genes involved in oxidative phosphorylation are coordinately downregulated in human diabetes. Nat Genet 34: 267-273, 2003.

20. Chou YS, Yen CC, Chen WM, Lin YC, Wen YS, Ke WT, Wang JY, Liu CY, Yang MH, Chen TH and Liu CL: Cytotoxic mechanism of PLK1 inhibitor GSK461364 against osteosarcoma: Mitotic arrest, apoptosis, cellular senescence, and synergistic effect with paclitaxel. Int J Oncol 48: 1187-1194, 2016.

21. Mosmann T: Rapid colorimetric assay for cellular growth and survival: Application to proliferation and cytotoxicity assays. J Immunol Methods 65: 55-63, 1983.

22. Chou TC and Talalay P: Quantitative analysis of dose-effect relationships: The combined effects of multiple drugs or enzyme inhibitors. Adv Enzyme Regul 22: 27-55, 1984.

23. Schmit TL, Nihal M, Ndiaye M, Setaluri V, Spiegelman VS and Ahmad N: Numb regulates stability and localization of the mitotic kinase PLK1 and is required for transit through mitosis. Cancer Res 72: 3864-3872, 2012

24. Zhu Y, Xu L, Zhang J, Hu X, Liu Y, Yin H, Lv T, Zhang H, Liu L, An H, et al: Sunitinib induces cellular senescence via p53/ Dec1 activation in renal cell carcinoma cells. Cancer Sci 104: 1052-1061, 2013.

25. Muller-Tidow C, Metzger R, Kügler K, Diederichs S, Idos G, Thomas M, Dockhorn-Dworniczak B, Schneider PM, Koeffler HP, Berdel WE and Serve H: Cyclin E is the only cyclin-dependent kinase 2-associated cyclin that predicts metastasis and survival in early stage non-small cell lung cancer. Cancer Res 61: 647-653, 2001.

26. Lens SM, Voest EE and Medema RH: Shared and separate functions of polo-like kinases and aurora kinases in cancer. Nat Rev Cancer 10: 825-841, 2010.

27. Kelly KR, Ecsedy J, Medina E, Mahalingam D, Padmanabhan S, Nawrocki ST, Giles FJ and Carew JS: The novel Aurora A kinase inhibitor MLN8237 is active in resistant chronic myeloid leukaemia and significantly increases the efficacy of nilotinib. J Cell Mol Med 15: 2057-2070, 2011.

28. Qi W, Cooke LS, Liu X, Rimsza L, Roe DJ, Persky AM, Miller TP and Mahadevan D: Aurora inhibitor MLN8237 in combination with docetaxel enhances apoptosis and anti-tumor activity in mantle cell lymphoma. Biochem Pharmacol 81: 881-890, 2011.

29. Kuilman T and Peeper DS: Senescence-messaging secretome: SMS-ing cellular stress. Nat Rev Cancer 9: 81-94, 2009.

30. Schoffski P, Chawla S, Maki RG, Italiano A, Gelderblom H, Choy E, Grignani G, Camargo V, Bauer S, Rha SY, et al: Eribulin versus dacarbazine in previously treated patients with advanced liposarcoma or leiomyosarcoma: A randomised, open-label, multicentre, phase 3 trial. Lancet 387: 1629-1637, 2016.

31. Demetri GD, Schöffski P, Grignani G, Blay JY, Maki RG, Van Tine BA, Alcindor T, Jones RL, D'Adamo DR, Guo M and Chawla S: Activity of eribulin in patients with advanced liposarcoma demonstrated in a subgroup analysis from a randomized phase III study of Eribulin versus dacarbazine. J Clin Oncol 35: 3433-3439, 2017.

32. Demetri GD, von Mehren M, Jones RL, Hensley ML, Schuetze SM, Staddon A, Milhem M, Elias A, Ganjoo K, Tawbi H, et al: Efficacy and safety of trabectedin or dacarbazine for metastatic liposarcoma or leiomyosarcoma after failure of conventional chemotherapy: Results of a phase III randomized multicenter clinical trial. J Clin Oncol 34: 786-793, 2016.

33. Chu CY, Chen CF, Rajendran RS, Shen CN, Chen TH, Yen CC, Chuang CK, Lin DS and Hsiao CD: Overexpression of Akt1 enhances adipogenesis and leads to lipoma formation in zebrafish. PLoS One 7: e36474, 2012.

34. Fletcher CD, Akerman M, Dal Cin P, de Wever I, Mandahl N, Mertens F, Mitelman F, Rosai J, Rydholm A, Sciot R, et al: Correlation between clinicopathological features and karyotype in lipomatous tumors. A report of 178 cases from the chromosomes and morphology (CHAMP) Collaborative study group. Am J Pathol 148: 623-630, 1996. 
35. Dei Tos AP, Doglioni C, Piccinin S, Sciot R, Furlanetto A, Boiocchi M, Dal Cin P, Maestro R, Fletcher CD and Tallini G: Coordinated expression and amplification of the MDM2, CDK4, and HMGI-C genes in atypical lipomatous tumours. J Pathol 190: 531-536, 2000 .

36. Lagarde P, Perot G, Kauffmann A, Brulard C, Dapremont V, Hostein I, Neuville A, Wozniak A, Sciot R, Schoffski P, et al Mitotic checkpoints and chromosome instability are strong predictors of clinical outcome in gastrointestinal stromal tumors. Clin Cancer Res 18: 826-838, 2012.

37. Dickson MA, Mahoney MR, Tap WD, D'Angelo SP, Keohan ML, Van Tine BA, Agulnik M, Horvath LE, Nair JS and Schwartz GK: Phase II study of MLN8237 (Alisertib) in advanced/metastatic sarcoma. Ann Oncol 27: 1855-1860, 2016.
38. Huck JJ, Zhang M, McDonald A, Bowman D, Hoar KM, Stringer B, Ecsedy J, Manfredi MG and Hyer ML: MLN8054, an inhibitor of Aurora A kinase, induces senescence in human tumor cells both in vitro and in vivo. Mol Cancer Res 8: 373-384, 2010.

39. Campisi J and d'Adda di Fagagna F: Cellular senescence: When bad things happen to good cells. Nat Rev Mol Cell Biol 8: 729-740, 2007.

40. Dimri GP, Lee X, Basile G, Acosta M, Scott G, Roskelley C, Medrano EE, Linskens M, Rubelj I, Pereira-Smith O, et al: A biomarker that identifies senescent human cells in culture and in aging skin in vivo. Proc Natl Acad Sci USA 92: 9363-9367, 1995. 